\title{
Perspectives on gender parity in bioanalysis: an interview with Nikunj Tanna
}

\author{
Nikunj Tanna*,1 \\ ${ }^{1}$ Scientific Operations, Waters Corporation, Milford, MA 01757, USA \\ *Author for correspondence: Nikunj_Tanna@waters.com
}

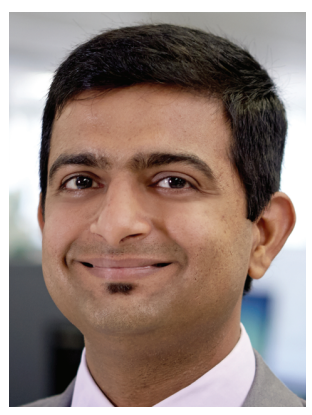

\begin{abstract}
Biography:
Nikunj Tanna is a senior scientist in the Scientific Operations department at Waters Corporation, focusing on quantification of small and large molecules for pharmaceutical, biopharmaceutical and clinical diagnostics applications. He previously led the clinical diagnostics team at Berg LLC, a Framingham, MA, USA-based biotech and clinical stage company. He feeds his curiosity with nuanced conversations with people from all walks of life. He is an avid Chelsea FC fan and loves to cook and travel. He is a proud rider of the Pan-Mass Challenge, which is a cross state bicycle ride to raise funds to support cancer research at the Dana Farber Cancer Institute in Boston, MA, USA.
\end{abstract}

Accepted for publication: 5 March 2019; Published online: 18 April 2019

What advice would you give to young women hoping to embark on a career in the field?

The most important advice for any early career professional would be to believe in yourself, be honest and give it your best shot. Do not be afraid to take chances with your career choices and do not be afraid to voice your opinion.

\section{How can mentors help women in their career development?}

A mentor's role is to empower the mentees. To allow them to express themselves and provide constructive discussions around their strengths and areas for improvement. It is important for the mentor-mentee relationship to be built upon trust and mutual respect.

\section{How important it is to have a short-term \& long-term goals in your career?}

I think that depends a lot on individuals and every individuals journey and goals are different. For some people, having very clearly defined short- and long-term goals is extremely critical and provides the fuel which enables them to achieve those goals. Others may be more inclined to give it their all and enjoy the journey, wherever it takes them, which is equally admirable and important. In both cases, being true to yourself, and being nimble in adapting to the situation at hand is vital. The more you know yourself, your judgement of your strengths, weaknesses and goals may evolve. And that is okay.

\section{What advice would you give to women hoping to pursue senior-level scientific positions?}

The thought process, approach and management styles between men and women are different. And the most successful companies, workplaces and organizations embrace and encourage these differences. My advice to any women who are in or aspire to be in leadership positions would be to acknowledge that what you bring to the table is complimentary to your male counterparts. Do not change 'your way' to fit in with the current male-dominated norms. 'Your way' is your biggest strength.

\section{What are the most valuable skill sets diversity bring to an organization?}

Diversity in every form helps disband notions and assumptions about that minority group. Diversity forces a group/team in which these individuals participate, to think about how the question at hand can affect different people from different backgrounds. You can draw on peoples varied personal experiences to make the project more well-rounded and complete. Women generally have more empathy, are able to assimilate and digest information 
from a wider range of avenues and may be able to assess broader impact. Most of all, more diversity generally leads to more respect for people who look, talk and have life experiences different from ours.

\section{What do you see as being the most effective solution to getting more women involved in STEM careers?}

Starting early is key. Exposing young girls to STEM in a fun, engaging way is important. Equally important is to ensure that these young adults have the resources and mentors at every step in their decision-making process. It is also important to raise awareness about the possible financial benefits and stability a STEM career can provide. This is equally important.

Another issue in today's world of social media is the image of a scientist. The current image of a scientist for most kids is a guy in a white lab coat, big glasses holding a flask with colored liquid. This visual needs to change. A STEM career needs to look as appealing and needs to have as much fan fare as a sports or entertainment career.

\section{If you were asked to create a specific framework in your business to encourage more gender parity how will you do that?}

The easy solution is to require equal representation at every level for men and women. Personally, I do not think that is the best way to deal with the bias at hand. You want to pick the best candidate to do the job. For example, when reviewing resumes, blinding the name, gender, ethnicity of the candidate and judging the credentials based solely on experience and skills is one way. You would still have to deal with unconscious bias when the candidate comes in for the interview. That is a lot harder. It has to be a very conscious effort on the part of the organization to require all employees to undergo unconscious bias training.

This one is a no brainer - equal pay for men and women doing the same job.

One of the more controversial ones is equal forced paid paternity leave. Most women generally take between 6 and 12 weeks of maternity leave in USA (some without full pay). This is an incredibly important time for the mother to recover and bond with her child. But those 3 months out of work could be the difference between her or her male counterpart getting promoted. Requiring men to take the same amount of time off as women after parenthood levels the playing field somewhat, and also give the father the same kind of quality time with the child to bond.

\section{Disclaimer}

The opinions expressed in this interview are those of the interviewee and do not necessarily reflect the views of Waters Corporation or Future Science Group.

Financial \& competing interests disclosure

The author has no relevant affiliations or financial involvement with any organization or entity with a financial interest in or financial conflict with the subject matter or materials discussed in the manuscript. This includes employment, consultancies, honoraria, stock ownership or options, expert testimony, grants or patents received or pending, or royalties.

No writing assistance was utilized in the production of this manuscript. 